\title{
The Debut of Schizophrenia in the Context of Entropy Neuron-Glial Network of the Brane
}

\author{
Rosman SV* \\ Physician of functional diagnostics of SBIH, Regional psychoneurological clinic, Russia
}

Submission: August 22, 2017; Published: September 06, 2017

*Corresponding author: Rosman SV, Physician of functional diagnostics of SBIH, Regional psychoneurological clinic, Tver, Russian Federation, Russia, Tel: +7-903-800-11-05; Email: seros2005@mail.ru

\begin{abstract}
In article attempt of systematization of the neurophysiologic changes observed during the onset of schizophrenia using a new technique, the variance of the amplitude-frequency characteristics of the alpha rhythm for early detection of debut of schizophrenia, the identification of common regularities in the development of psychopathology, creating a natural-scientific systematization of mental illness on the basis of dimensioning neurophysiological methods.

Keywords: Debut of the schizophrenia; Entropy of the neuron-glial network of the brain; Dispersion of alpha-rhythm; Diagnosis of mental illness

Abbreviations: DSch: Debut of Paranoid Schizophrenia (F20.09x ICD-10); MMR: Mild Mental retardation(F70.x ICD-10); PD: Personality disorder (F60.x ICD-10); DAFCAR: Dispersion of Amplitude-Frequency Characteristics of the alpha rhythm EEG; NGNB: Neuron-Glial Network of the brain; HVT: Hyperventilation test; CDol: Coefficient of Dispersion of alpha-Rhythm EEG-1(the quotient of the modal values of power of alpha rhythm to his total power in the range of 7-13 Hz); CD 22: Coefficient of Dispersion of the alpha-Rhythm EEG-2 (the quotient of the power of the alpha rhythm in the range of "a modal value $\pm 0.5 \mathrm{~Hz}$ " to his total power in the range of 7-13 Hz); $0 \mathrm{Mo}$ : Value of the Modal Frequencies in Occipital Electrodes; F Mo f: Value of the Modal Frequencies in Frontal Electrodes; 0 Mo f - F Mo f: Value of the Difference of Modal Frequencies Between the Occipital and Frontal Electrodes; IIDA: Integral Index of Dispersion of the Alpha rhythm EEG(Value of the Kurtosis of the Normal Distribution CD $\alpha$ in the Occipital Electrodes); ADA: Asymmetry Distribution of the Alpha rhythm EEG (Value of the Asymmetry Distribution CD $\alpha \mathrm{l}$ in the Occipital Electrodes); IIH: Value of the Index Hypofrontality (Kurtosis of the Normal Distribution CDol in the Frontal Electrodes); AH: Value of the Asymmetry of CD $\alpha$ lin the Frontal Electrodes; CV\% - the coefficient of variation; CI: Confidence interval; c.u.: conditional unit
\end{abstract}

\section{Introduction}

In medical literature the problem of schizophrenia is so widely represented that there is no need for lengthy introduction in evidence the medico-social significance of timely diagnosis of schizophrenia [1,2]. Schizophrenia - the embodiment of the psychiatry in the diversity of symptoms and clinical manifestations of psychopathology. Not passed this disease and the main feature of psychiatry - despite the diversity of literature that the best minds of medicine pondered its problems, to date, no objective marker of schizophrenia. All diagnostics it is based on abstract subjective reasoning. This feature generates an extremely wide interpretation of the behavioral characteristics of people, every deviation from the accepted rules and traditions can be interpreted as a manifestation of schizophrenia. Even the fact of writing some alert psychiatrists can easily be regarded as a manifestation of schizophrenia, the author, as the desire for "the mad perfectionism" grandeur of conception and the desire to solve the world's problems included in the diagnostic criteria for this mental disorder.
However, I must reassure such critics in my plans do not include a search for markers of schizophrenia, since such complex processes in the brain cannot be described by several parameters, moreover, that physical and intellectual capabilities of a single researcher is unable to provide the identification of all parameters that occur in the brain changes in health and disease. Is no exception and systematization of schizophrenia in the framework of psychopathology [1,2]. Disputes about the ownership of schizophrenia among different groups of mental illnesses will cease only after the discovery of their naturalscientific reasons.

It should be said that very many of the effects from the EEG in schizophrenia has been repeatedly described in the literature [3-19]. However, they often wore a qualitative nature and was more of a retrospective statistical indicators, not suitable for the operational needs of the clinic [7]. The psychic activity of man has in common with the manifestations of social psychology society since the administrative mechanisms and human and 


\section{Global Journal of Addiction \& Rehabilitation Medicine}

society are one. No wonder why there are concepts of "social schizophrenia", "social hysteria". Knowledge of the causes of psychopathology will help us, sooner or later, to understand the basic causes of social problems. The debut of schizophrenia is important because, for the most part, the manifestations of it are erased character, is indistinguishable from borderline psychopathology, which we wrote as part of a cycle of articles devoted to DAFCAR timely differential diagnosis with other forms of mental illness - an urgent problem of modern medicine.

a. The purpose of the study: To identify basic laws of entropy NGNB at the debut of schizophrenia using the method of determining the parameters DAFCAR.

\section{Materials and methods}

Table 1: The distribution of patients in the comparative experiment study on DAFCAR among certain types of psychopathology.

\begin{tabular}{|c|c|c|c|c|c|}
\hline Nosological form & men & Age & women & Age & Total \\
\hline DSch (F20.09x) & 23 & $29.0 \pm 0.9$ & 58 & $27.1 \pm 1.2$ & 81 \\
\hline MMR (F70.x) & 45 & $28.6 \pm 0,8$ & 65 & $27.4 \pm 1,3$ & 110 \\
\hline PD (F60.x) & 40 & $22.7 \pm 1.1$ & 98 & $22.9 \pm 0,5$ & 138 \\
\hline Control & 15 & $34.1 \pm 0,5$ & 60 & $21.5 \pm 0,6$ & 74 \\
\hline Total & $\mathbf{1 2 1}$ & & $\mathbf{2 8 2}$ & $\mathbf{4 0 3}$ \\
\hline
\end{tabular}

Performed by standard procedure of the EEG electrodes according to international system "10-20\%" and the ipsilateral ear referent electrodes [16] test with hyperventilation was performed by the standard method with the dispersion assessment of the changes of alpha-rhythm method S. V. Rosman (2017). Parameters D is calculated according to the method of S. V. Rosman (2013) using the programs Microsoft Excel and Statistica 10.0. For studies of selected young and middle-aged patients to exclude the effects of age-related changes, with minimal opportunity for comorbidity and minimize hazards, despite the fact that about $40 \%$ of patients with schizophrenia Discussion abuse alcohol and drugs. All patients the study was carried out during the therapy with psychotropic and sedative drugs the distribution of patients according to groups are presented in Table 1.

\section{Results}

According to the tradition adopted in this series of articles, assessment of results will start with the semi-subjective, semidimensioning method of dispersion mapping of the alpha rhythm.

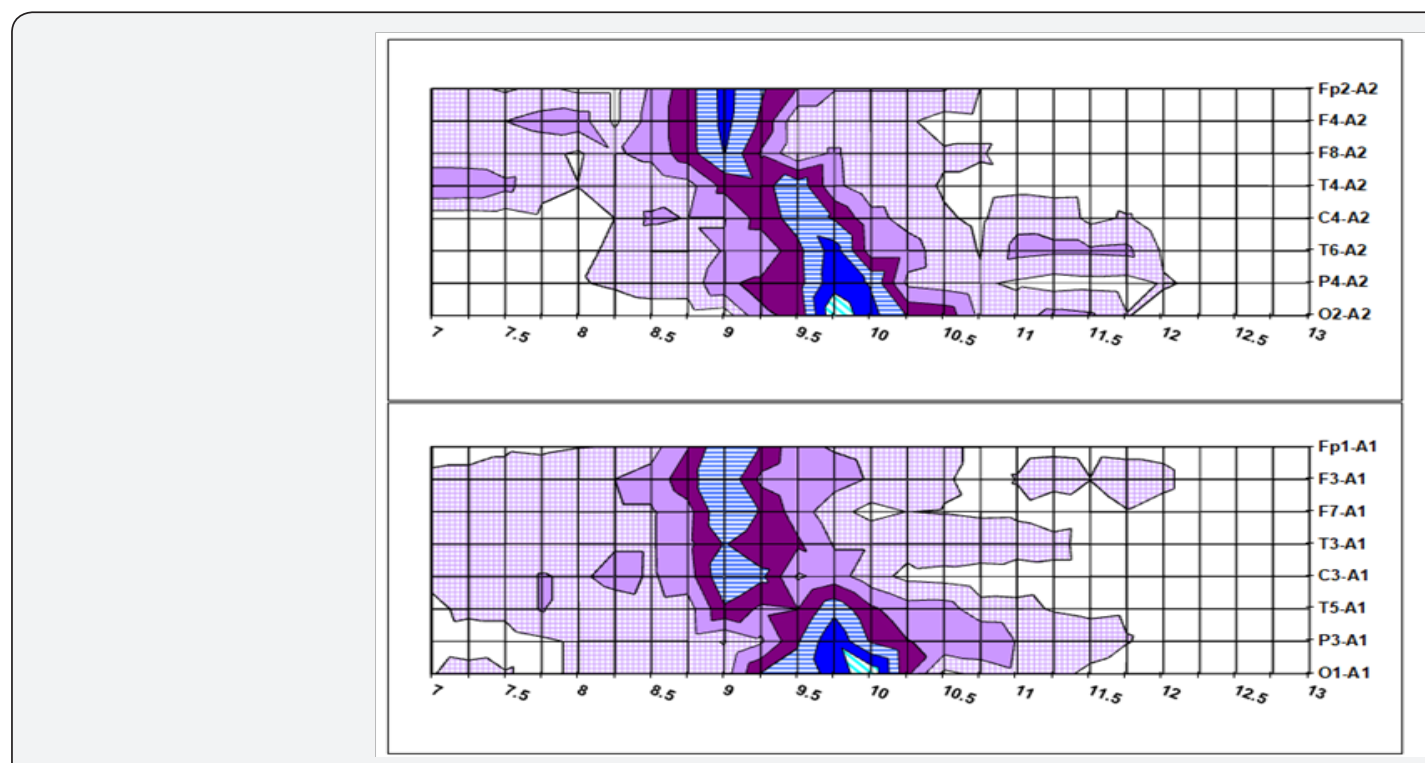

Figure 1: The average dispersion index of the alpha rhythm at the onset of schizophrenia in men. Here and further the upper cartograms - the left hemisphere, bottom - right hemisphere; on the horizontal axis is the frequency of the alpha rhythm, Hz; vertical axis - EEG. Explanation - in the section discussion of results.

The results obtained provide a wide field for discussion. Comparative analysis of dispersion maps at various psychopathology shows that the main feature of the debut of schizophrenia is a marked slowing of the alpha rhythm in the frontal lobes more than $0.5 \mathrm{~Hz}$, often about $1 \mathrm{~Hz}$ (Figure 1). This confirms numerous observations on the emergence of a slow wave, usually in the range of theta oscillations activity. Here, however, it becomes obvious that this is not an isolated occurrence of some oscillations, namely, the total slowing of the alpha rhythm, in which there are intermediate frequency oscillations in the form of dispersion, the dispersion around the modal values with a shift in slow-wave region. The frequency of 


\section{Global Journal of Addiction \& Rehabilitation Medicine}

the alpha rhythm in the other parts of the brain in the normal range, although the dispersion around the modal frequency is there.

A feature of cartograms in women is somewhat smaller difference of modal frequencies between frontal and occipital derivations and more than men, a shift of modal frequencies in the slow-wave region in the other leads (temporal and Central)
(Figure 2). The reason for this is difficult to explain may need a more extensive sample of observations in order to make valid conclusions. Comparative cartograms for individual nosological forms shows that there is a tendency to shift the frontal complex of the cartogram to the left, for slow values of the alpha rhythm in the range from normal to schizophrenia (Figure 3). Statistics indexes DAFCAR supported by the observations of detectable dispersion maps.

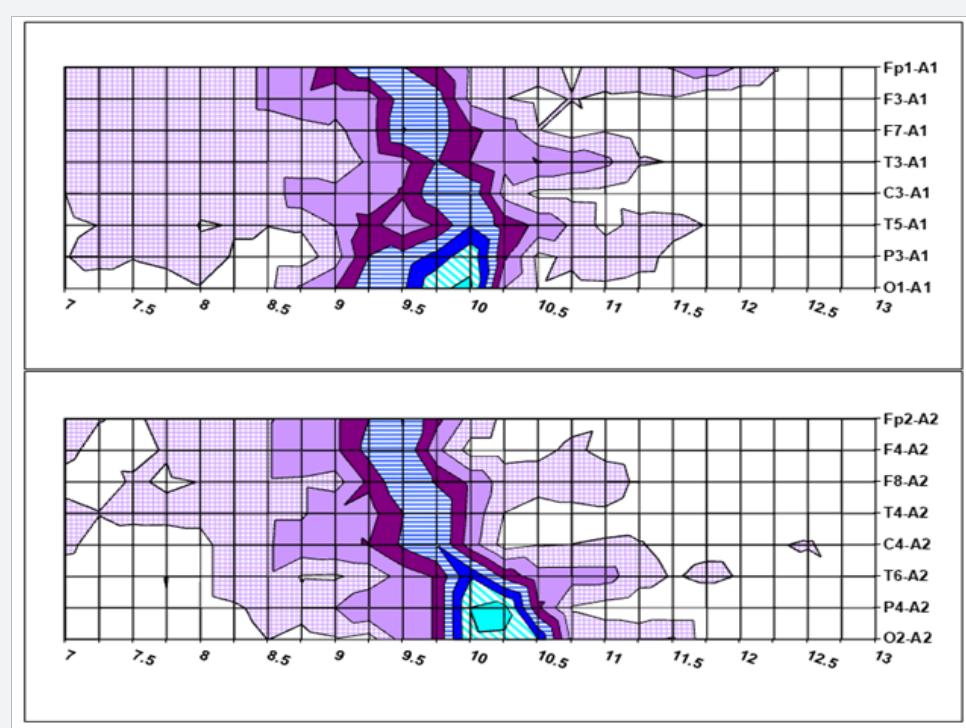

Figure 2: The average dispersion index of the alpha rhythm at the debut of schizophrenia in women.

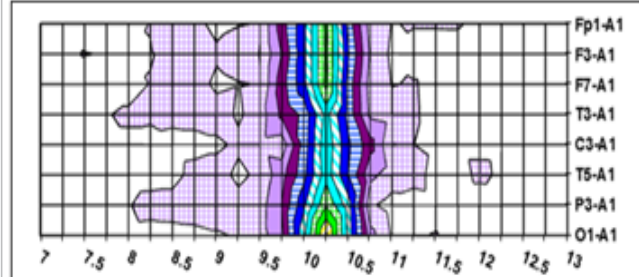

A

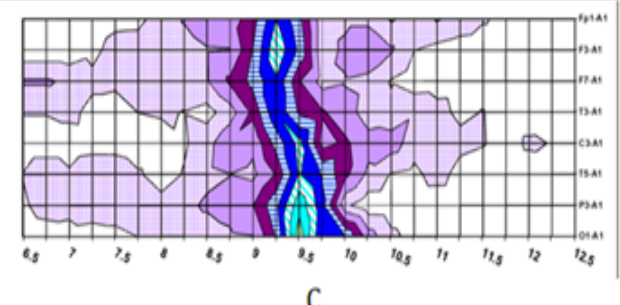

C

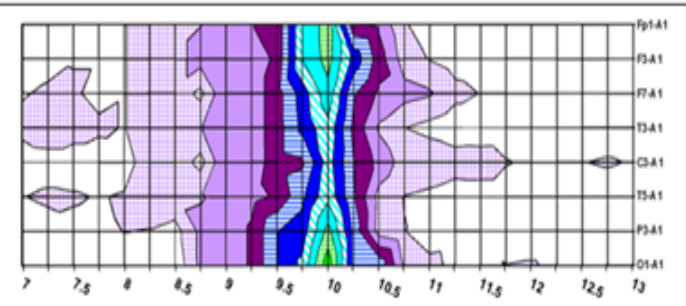

B

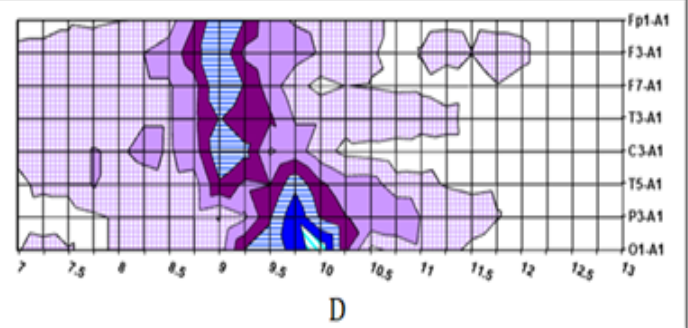

D

Figure 3: Comparative average dispersion cartograms in norm and in various forms of psychopathology (left hemisphere): A - normal, B personality disorder, C - mild mental retardation, D is the debut of schizophrenia

In the comparative statistical tables are clearly visible differences in index values among the different nosological forms. But this is most clearly seen on the histograms (Figures $4 \& 5)$. If there are no differences in the occipital leads of the modal frequencies ( $\mathrm{O}$ Mo f) significant age-melts the distinction between frontal and occipital derivations ( $\mathrm{O}$ Mo f - F Mo f), reaching $1 \mathrm{~Hz}$, while for women this value is slightly lower, but above $0.5 \mathrm{~Hz}$ boundary values of the norm. Comparison of the average values of these coefficients by Student's criterion shows that these differences are statistically valid and significantly expressed (Tables 2-5). The General trend of all indexes in a number of pathologies, built along the "axis of dementia", which was discussed in previous publications, is to reduce them, starting with standards and ending with schizophrenia (Figure 6). 
Table 2: Summary comparative statistics indexes DAFCAR in norm and in some forms of psychopathology (frontal abduction).

\begin{tabular}{|c|c|c|c|c|c|c|c|c|c|c|}
\hline \multirow{3}{*}{ Gender } & \multirow{3}{*}{ Hemisphere } & \multirow{3}{*}{ Index } & \multicolumn{2}{|c|}{ DSch } & \multicolumn{2}{|c|}{ Control } & \multicolumn{2}{|c|}{ PD } & \multicolumn{2}{|c|}{ MMR } \\
\hline & & & Mean & CV\% & Mean & CV\% & Mean & CV\% & Mean & CV\% \\
\hline & & & \multicolumn{2}{|c|}{ Confidence $\pm 95 \%$} & \multicolumn{2}{|c|}{ Confidence $\pm 95 \%$} & \multicolumn{2}{|c|}{ Confidence $\pm 95 \%$} & \multicolumn{2}{|c|}{ Confidence $\pm 95 \%$} \\
\hline & \multirow{14}{*}{ Left } & \multirow{2}{*}{$\mathrm{AH}$} & 1.299 & 61 & 2.575 & 14 & 1.998 & 43 & 1.743 & 52 \\
\hline & & & \multicolumn{2}{|c|}{$1.091-1.507$} & \multicolumn{2}{|c|}{$2.32-2.83$} & \multicolumn{2}{|c|}{$1.825-2.171$} & \multicolumn{2}{|c|}{$1.519-1.966$} \\
\hline & & \multirow{2}{*}{ Age } & 27.1 & 28 & 20.3 & 16 & 22.9 & 29 & 27.4 & 39 \\
\hline & & & \multicolumn{2}{|c|}{$25-29.1$} & \multicolumn{2}{|c|}{ 19.1-21.6 } & 21.6 & & 24 & \\
\hline & & \multirow{4}{*}{$\begin{array}{l}\text { CD } \alpha 1 \\
\text { CD } \alpha 1\end{array}$} & 0.127 & 43 & 0.224 & 23 & 0.19 & 45 & 0.165 & 44 \\
\hline & & & 0.11 & 141 & 0.18 & 62 & 0.173 & 207 & 0.14 & 83 \\
\hline & & & 0.389 & 33 & 0.588 & 18 & 0.529 & 28 & 0.486 & 30 \\
\hline & & & 0.35 & 423 & 0.50 & 72 & 0.49 & 559 & 0.4 & 21 \\
\hline & & $\Gamma M$ & 8.99 & 12 & 10.2 & 5 & 10 & 7 & 9.57 & 8 \\
\hline & & F IVIO I & 8.7 & & 9.89 & & 9.85 & & 9.3 & \\
\hline & & O Mo f - & 0.91 & 128 & 0.05 & 1249 & 0.05 & 414 & 0.11 & 210 \\
\hline & & F Mo f & & & -0.0 & & 0.0 & & 0.0 & \\
\hline & & HU & 1.955 & 157 & 6.908 & 29 & 4.458 & 86 & 3.592 & 109 \\
\hline mon & & 114 & 1.14 & 764 & 5.50 & 307 & 3.693 & 24 & 2.62 & 61 \\
\hline men & & $\Delta H$ & 1.162 & 74 & 2.542 & 14 & 2.024 & 41 & 1.741 & 48 \\
\hline & & АП & 0.93 & 387 & 2.32 & & $1.85 \varepsilon$ & 91 & 1.53 & 48 \\
\hline & & $\Delta \sigma 0$ & 27.1 & 28 & 20.3 & 16 & 22.9 & 29 & 27.4 & 39 \\
\hline & & Age & & & 19. & & 21.6 & & 24 & \\
\hline & & $C D a 1$ & 0.121 & 43 & 0.221 & 19 & 0.191 & 44 & 0.164 & 44 \\
\hline & & $\operatorname{CD} \alpha 1$ & 0.10 & 135 & 0.19 & 48 & 0.17 & 208 & 0.14 & 82 \\
\hline & Dight & $C D \sim 1$ & 0.377 & 33 & 0.589 & 18 & 0.535 & 27 & 0.48 & 30 \\
\hline & Kignt & CDO1 & 0.3 & 41 & 0.51 & 67 & 0.50 & 664 & 0.44 & 16 \\
\hline & & FMof & 8.91 & 11 & 10.2 & 5 & 9.93 & 7 & 9.49 & 11 \\
\hline & & F MO I & 8.6 & & 9.8 & & 9.79 & & 9.2 & \\
\hline & & O Mo f - & 0.89 & 131 & 0.03 & 0 & 0.08 & 391 & 0.18 & 646 \\
\hline & & F Mo f & & & -0.0 & & 0.02 & & -0.1 & \\
\hline & & WU & 1.579 & 201 & 6.698 & 31 & 4.498 & 85 & 3.357 & 110 \\
\hline & & ПП & 0.74 & 412 & 5.29 & 97 & 3.725 & 66 & 2.44 & 69 \\
\hline & & $H$ & 1.112 & 63 & 2.218 & 13 & 1.775 & 34 & 1.802 & 46 \\
\hline & & AH & 0.81 & 412 & 2.19 & 75 & 1.462 & 89 & 1.5 & \\
\hline & & $A_{0}$ & 29 & 29 & 33.4 & 37 & 24.2 & 22 & 28.6 & 42 \\
\hline & & Age & 25 & & 26 & & 21.2 & & 24 & \\
\hline & & $C D \sim 1$ & 0.115 & 42 & 0.188 & 27 & 0.164 & 32 & 0.17 & 46 \\
\hline & & CDO1 & 0.09 & 135 & 0.17 & 43 & 0.13 & & 0.14 & 93 \\
\hline & & $C D \times 1$ & 0.38 & 34 & 0.571 & 18 & 0.499 & 21 & 0.485 & 27 \\
\hline women & Left & $\mathrm{CD} \alpha 1$ & 0.32 & 436 & 0.53 & & $0.44 \epsilon$ & 52 & 0.44 & 24 \\
\hline & & 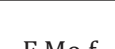 & 9.41 & 13 & 10.37 & 5 & 10.01 & 6 & 9.51 & 9 \\
\hline & & F IVIO I & 8.8 & & 9.72 & & 9.67 & & 9.2 & \\
\hline & & $\begin{array}{l}\text { O Mo f - } \\
\text { F Mo f }\end{array}$ & 0.62 & 175 & 0.21 & 295 & 0.17 & 217 & 0.14 & 223 \\
\hline & & & 0.1 & & -0.0 & & -0.0 & & 0.0 & \\
\hline & & IIH & 1.002 & 228 & 4.641 & 28 & 3.328 & 93 & 3.76 & 108 \\
\hline & & & 0.0 & & 4.54 & 17 & $1.82 \varepsilon$ & 328 & 2.54 & 79 \\
\hline
\end{tabular}




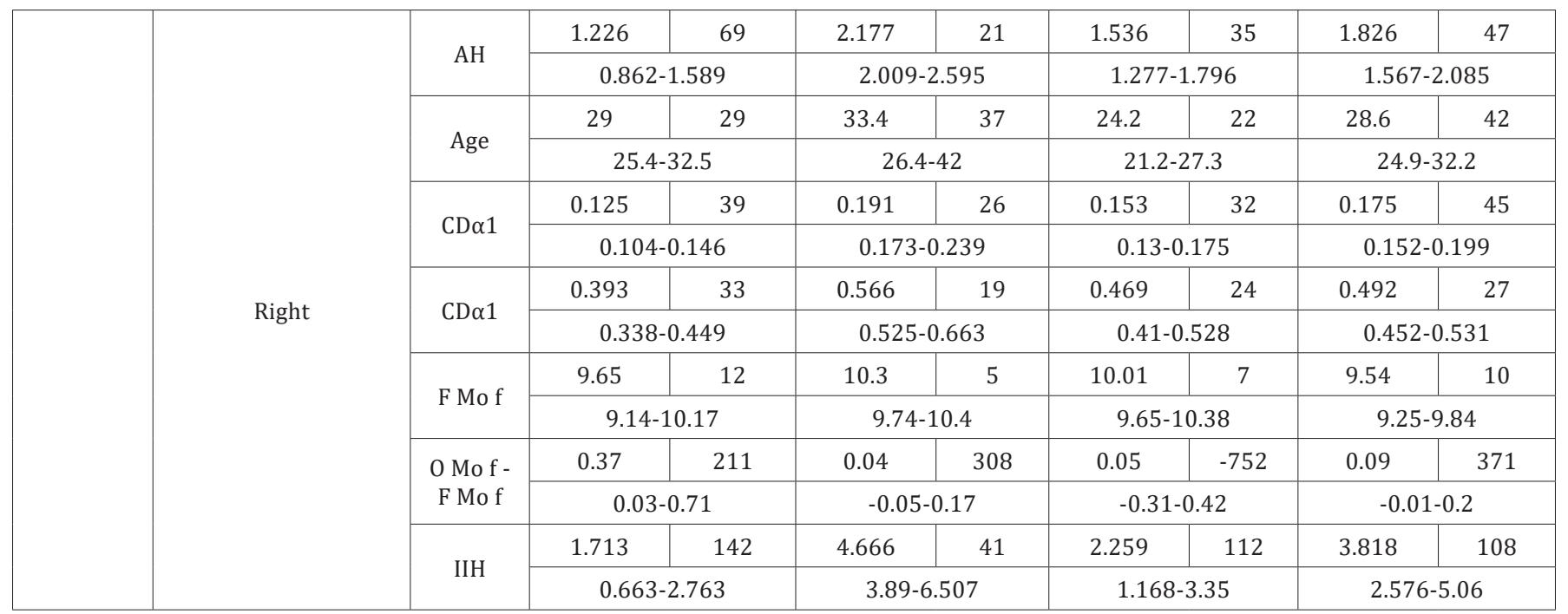

Table 3: Summary comparative statistics indexes DAFCAR in norm and in some forms of psychopathology (occipital abduction).

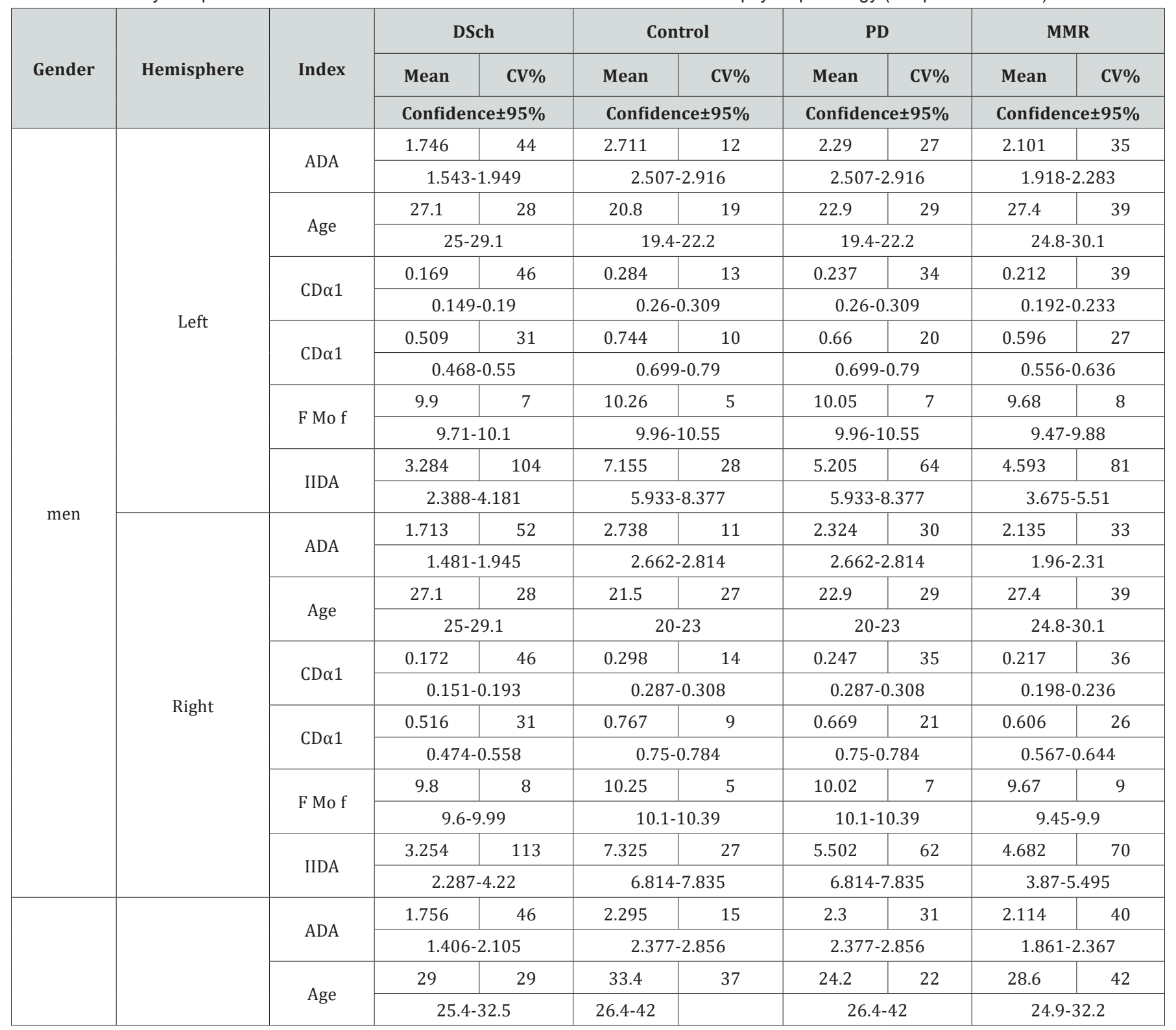


Global Journal of Addiction \& Rehabilitation Medicine

\begin{tabular}{|c|c|c|c|c|c|c|c|c|c|c|}
\hline & \multirow{8}{*}{ Left } & \multirow{2}{*}{$\mathrm{CD} \alpha 1$} & 0.176 & 44 & 0.246 & 19 & 0.233 & 36 & 0.218 & 43 \\
\hline & & & \multicolumn{2}{|c|}{$0.142-0.21$} & \multicolumn{2}{|c|}{$0.249-0.317$} & \multicolumn{2}{|c|}{$0.249-0.317$} & \multicolumn{2}{|c|}{$0.19-0.246$} \\
\hline & & \multirow{2}{*}{$\mathrm{CD} \alpha 1$} & 0.548 & 28 & 0.715 & 9 & 0.641 & 23 & 0.61 & 26 \\
\hline & & & \multicolumn{2}{|c|}{$0.481-0.614$} & \multicolumn{2}{|c|}{$0.723-0.806$} & \multicolumn{2}{|c|}{$0.723-0.806$} & \multicolumn{2}{|c|}{$0.562-0.657$} \\
\hline & & \multirow{2}{*}{ F Mo f } & 10.03 & 8 & 10.58 & 5 & 10.17 & 7 & 9.65 & 9 \\
\hline & & & \multicolumn{2}{|c|}{$9.69-10.37$} & \multicolumn{2}{|c|}{$9.8-10.43$} & \multicolumn{2}{|c|}{$9.8-10.43$} & \multicolumn{2}{|c|}{ 9.4-9.9 } \\
\hline & & \multirow{2}{*}{ IIDA } & 3.082 & 117 & 4.804 & 34 & 5.455 & 61 & 4.775 & 89 \\
\hline & & & \multicolumn{2}{|c|}{$1.527-4.638$} & \multicolumn{2}{|c|}{$5.061-7.787$} & \multicolumn{2}{|c|}{$5.061-7.787$} & \multicolumn{2}{|c|}{$3.492-6.059$} \\
\hline \multirow{12}{*}{ women } & \multirow{12}{*}{ Right } & \multirow{2}{*}{$\mathrm{ADA}$} & 1.788 & 47 & 2.514 & 17 & 2.33 & 31 & 2.148 & 36 \\
\hline & & & \multicolumn{2}{|c|}{$1.427-2.148$} & \multicolumn{2}{|c|}{$2.257-2.77$} & \multicolumn{2}{|c|}{$2.257-2.77$} & \multicolumn{2}{|c|}{$1.916-2.381$} \\
\hline & & \multirow{2}{*}{ Age } & 29 & 29 & 34.1 & 36 & 22.7 & 23 & 28.6 & 42 \\
\hline & & & \multicolumn{2}{|c|}{$25.4-32.5$} & \multicolumn{2}{|c|}{$26.6-41.5$} & \multicolumn{2}{|c|}{$26.6-41.5$} & \multicolumn{2}{|c|}{$24.9-32.2$} \\
\hline & & \multirow{2}{*}{$\mathrm{CD} \alpha 1$} & 0.18 & 42 & 0.269 & 18 & 0.25 & 37 & 0.226 & 42 \\
\hline & & & 0.1 & & & & 0.2 & & 0.19 & \\
\hline & & $C D \propto 1$ & 0.529 & 30 & 0.76 & 10 & 0.673 & 21 & 0.622 & 27 \\
\hline & & Dat & 0.4 & & & & 0.71 & & 0.57 & \\
\hline & & $F M \circ f$ & 10.02 & 11 & 10.15 & 5 & 10.07 & 7 & 9.64 & 9 \\
\hline & & r INOO 1 & & & & & $9.8^{\prime}$ & & & \\
\hline & & UDA & 3.444 & 112 & 5.862 & 37 & 5.676 & 65 & 4.896 & 76 \\
\hline & & 110\% & 1.7 & & & & 4.55 & & 3.77 & \\
\hline
\end{tabular}

Table 4: Comparative indicators of differences in the average values of certain parameters of the DSch compared with PD, MMR and normal by Student's test (t-value) - left hemisphere.

\begin{tabular}{|c|c|c|c|c|c|c|}
\hline Index & Leading & Feel & RL & t-value & df & $\mathbf{p}$ \\
\hline IIH & \multirow{7}{*}{ Frontal } & 1.68460 & 4.49157 & -5.79328 & 217 & 0.000000 \\
\hline $\mathrm{AH}$ & & 1.24547 & 2.01208 & -6.76473 & 217 & 0.000000 \\
\hline F Mo f & & 9.11111 & 9.99275 & -7.06731 & 217 & 0.000000 \\
\hline $\mathrm{CD} \alpha 1$ & & 0.12339 & 0.19003 & -6.47252 & 217 & 0.000000 \\
\hline $\mathrm{CD} \alpha 2$ & & 0.38662 & 0.53228 & -7.50631 & 217 & 0.000000 \\
\hline O Mo f - F Mo f & & 0.82716 & 0.07971 & 7.42211 & 217 & 0.000000 \\
\hline Age & & 27.6 & 22.9 & 4.92390 & 217 & 0.000002 \\
\hline IIDA & \multirow{5}{*}{ Occipital } & 3.22706 & 5.30798 & -4.29204 & 217 & 0.000027 \\
\hline $\mathrm{ADA}$ & & 1.74869 & 2.29505 & -5.53995 & 217 & 0.000000 \\
\hline $\mathrm{CD} \alpha 1$ & & 0.17134 & 0.23852 & -5.86781 & 217 & 0.000000 \\
\hline $\mathrm{CD} \alpha 2$ & & 0.52014 & 0.65839 & -6.92032 & 217 & 0.000000 \\
\hline \multirow[t]{2}{*}{ Age } & & 27.6 & 22.9 & 4.92390 & 217 & 0.000002 \\
\hline & & Feel & UO & t-value & df & $\mathrm{p}$ \\
\hline $\mathrm{IIH}$ & \multirow{5}{*}{ Frontal } & 1.68460 & 3.66107 & -3.80990 & 189 & 0.000188 \\
\hline $\mathrm{AH}$ & & 1.24547 & 1.76703 & -4.31092 & 189 & 0.000026 \\
\hline $\mathrm{CD} \alpha 1$ & & 0.12339 & 0.16701 & -4.49155 & 189 & 0.000012 \\
\hline $\mathrm{CD} \alpha 2$ & & 0.38662 & 0.48558 & -5.04963 & 189 & 0.000001 \\
\hline O Mo f - F Mo f & & 0.82716 & 0.12500 & 6.22506 & 189 & 0.000000 \\
\hline IIDA & \multirow{4}{*}{ Occipital } & 3.22706 & 4.66725 & -2.63676 & 189 & 0.009066 \\
\hline $\mathrm{ADA}$ & & 1.74869 & 2.10620 & -3.14007 & 189 & 0.001961 \\
\hline Mo f & & 9.93827 & 9.43182 & 5.55900 & 189 & 0.000000 \\
\hline \multirow[t]{2}{*}{$\mathrm{CD} \alpha 1$} & & 0.17134 & 0.21488 & -3.60239 & 189 & 0.000403 \\
\hline & & Feel & HOРMA & t-value & df & $\mathrm{p}$ \\
\hline
\end{tabular}


Global Journal of Addiction \& Rehabilitation Medicine

\begin{tabular}{|c|c|c|c|c|c|c|}
\hline IIH & \multirow{7}{*}{ Frontal } & 1.68460 & 6.49708 & -11.6109 & 153 & 0.000000 \\
\hline $\mathrm{AH}$ & & 1.24547 & 2.54202 & -13.1455 & 153 & 0.000000 \\
\hline Mof & & 9.11111 & 10.22635 & -7.6721 & 153 & 0.000000 \\
\hline $\mathrm{CD} \alpha 1$ & & 0.12339 & 0.22716 & -12.2568 & 153 & 0.000000 \\
\hline $\mathrm{CD} \alpha 2$ & & 0.38662 & 0.61661 & -12.1750 & 153 & 0.000000 \\
\hline O Mo f - F Mo f & & 0.82716 & 0.01689 & 6.0788 & 153 & 0.000000 \\
\hline Age & & 27.6 & 23.76 & 2.9302 & 153 & 0.003907 \\
\hline IIDA & \multirow{6}{*}{ Occipital } & 3.22706 & 6.98157 & -8.1989 & 153 & 0.000000 \\
\hline $\mathrm{ADA}$ & & 1.74869 & 2.68187 & -9.6224 & 153 & 0.000000 \\
\hline Mof & & 9.93827 & 10.24324 & -2.8356 & 153 & 0.005192 \\
\hline $\mathrm{CD} \alpha 1$ & & 0.17134 & 0.28597 & -11.4290 & 153 & 0.000000 \\
\hline $\mathrm{CD} \alpha 2$ & & 0.52014 & 0.74979 & -11.6987 & 153 & 0.000000 \\
\hline Age & & 27.6 & 23.76 & 2.9302 & 153 & 0.003907 \\
\hline
\end{tabular}

Table 5: Comparative indicators of differences in the average values of certain parameters of the DSch compared with PD, MMR and norma by Student's test (t-value) - right hemisphere.

\begin{tabular}{|c|c|c|c|c|c|c|}
\hline Index & Electrodes & DSch & PD & t-value & df & p \\
\hline IIH & \multirow{7}{*}{ Frontal } & 1.61701 & 4.22031 & -5.23236 & 217 & 0.000000 \\
\hline $\mathrm{AH}$ & & 1.18011 & 1.96491 & -6.67775 & 217 & 0.000000 \\
\hline F Mo f & & 9.11728 & 9.93297 & -6.58731 & 217 & 0.000000 \\
\hline $\mathrm{CD} \alpha 1$ & & 0.12199 & 0.18684 & -6.37945 & 217 & 0.000000 \\
\hline $\mathrm{CD} \alpha 2$ & & 0.38155 & 0.52572 & -7.49374 & 217 & 0.000000 \\
\hline O Mof - F Mo f & & 0.74383 & 0.09964 & 6.09897 & 217 & 0.000000 \\
\hline Age & & 27.6 & 22.9 & 4.92390 & 217 & 0.000002 \\
\hline IIDA & \multirow{5}{*}{ Occipital } & 3.30805 & 5.55234 & -4.48994 & 217 & 0.000012 \\
\hline ADA & & 1.73416 & 2.32583 & -5.52465 & 217 & 0.000000 \\
\hline $\mathrm{CD} \alpha 1$ & & 0.17413 & 0.24767 & -6.26731 & 217 & 0.000000 \\
\hline $\mathrm{CD} \alpha 2$ & & 0.51987 & 0.67014 & -7.32289 & 217 & 0.000000 \\
\hline \multirow[t]{2}{*}{ Age } & & 27.6 & 22.9 & 4.92390 & 217 & 0.000002 \\
\hline & & DSch & MMR & & & \\
\hline IIH & \multirow{5}{*}{ Frontal } & 1.61701 & 3.54592 & -3.75640 & 189 & 0.000229 \\
\hline $\mathrm{AH}$ & & 1.18011 & 1.77561 & -4.81181 & 189 & 0.000003 \\
\hline $\mathrm{CD} \alpha 1$ & & 0.12199 & 0.16870 & -4.86349 & 189 & 0.000002 \\
\hline $\mathrm{CD} \alpha 2$ & & 0.38155 & 0.48503 & -5.32562 & 189 & 0.000000 \\
\hline $\mathrm{O}-\mathrm{F}$ & & 0.74383 & 0.14545 & 4.08642 & 189 & 0.000065 \\
\hline IIDA & \multirow{4}{*}{ Occipital } & 3.30805 & 4.76974 & -2.80418 & 189 & 0.005571 \\
\hline ADA & & 1.73416 & 2.14052 & -3.51133 & 189 & 0.000558 \\
\hline Mo f & & 9.86111 & 9.42955 & 4.30106 & 189 & 0.000027 \\
\hline \multirow[t]{2}{*}{$\mathrm{CD} \alpha 1$} & & 0.17413 & 0.22057 & -3.87508 & 189 & 0.000147 \\
\hline & & DSch & Control & & & \\
\hline $\mathrm{IIH}$ & $\mathrm{F} 4-\mathrm{A} 2$ & 1.61701 & 6.17318 & -10.5081 & 153 & 0.000000 \\
\hline $\mathrm{AH}$ & $\mathrm{F} 4-\mathrm{A} 2$ & 1.18011 & 2.47694 & -11.7305 & 153 & 0.000000 \\
\hline F Mo f & $\mathrm{F} 4-\mathrm{A} 2$ & 9.11728 & 10.21959 & -7.7643 & 153 & 0.000000 \\
\hline $\mathrm{CD} \alpha 1$ & $\mathrm{~F} 4-\mathrm{A} 2$ & 0.12199 & 0.22614 & -12.5076 & 153 & 0.000000 \\
\hline $\mathrm{CD} \alpha 2$ & $\mathrm{~F} 4-\mathrm{A} 2$ & 0.38155 & 0.61728 & -12.6341 & 153 & 0.000000 \\
\hline O Mof - F Mo f & F4-A2 & 0.74383 & 0.01014 & 5.7213 & 153 & 0.000000 \\
\hline Age & $\mathrm{F} 4-\mathrm{A} 2$ & 27.6 & 23.76 & 2.9302 & 153 & 0.003907 \\
\hline IIDA & O2-A2 & 3.30805 & 7.06759 & -7.6884 & 153 & 0.000000 \\
\hline
\end{tabular}




\section{Global Journal of Addiction \& Rehabilitation Medicine}

\begin{tabular}{|c|c|c|c|c|c|c|}
\hline ADA & O2-A2 & 1.73416 & 2.69857 & -9.0017 & 153 & 0.000000 \\
\hline Mo f & O2-A2 & 9.86111 & 10.22973 & -3.2034 & 153 & 0.001653 \\
\hline CD 1 O2-A2 & 0.17413 & 0.29269 & -11.5525 & 153 & 0.000000 \\
\hline CD 2 & O2-A2 & 0.51987 & 0.76547 & -12.4230 & 153 & 0.000000 \\
\hline Age & O2-A2 & 27.6 & 23.76 & 2.9302 & 153 & 0.003907 \\
\hline
\end{tabular}
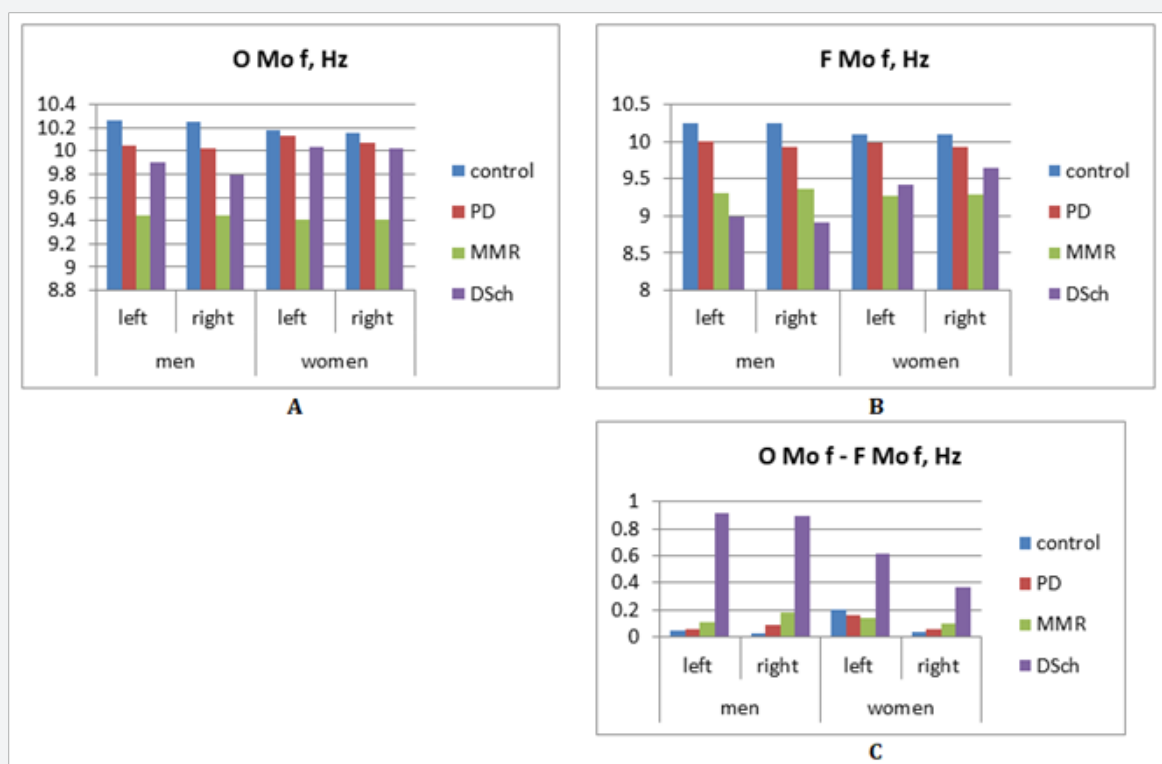

Figure 4: Comparative histogram of the average values of the modal frequency of the alpha rhythm at the debut of schizophrenia: $\mathrm{A}$ - in occipital leads, B - leads in the frontal, C - the difference between occipital and frontal derivations.

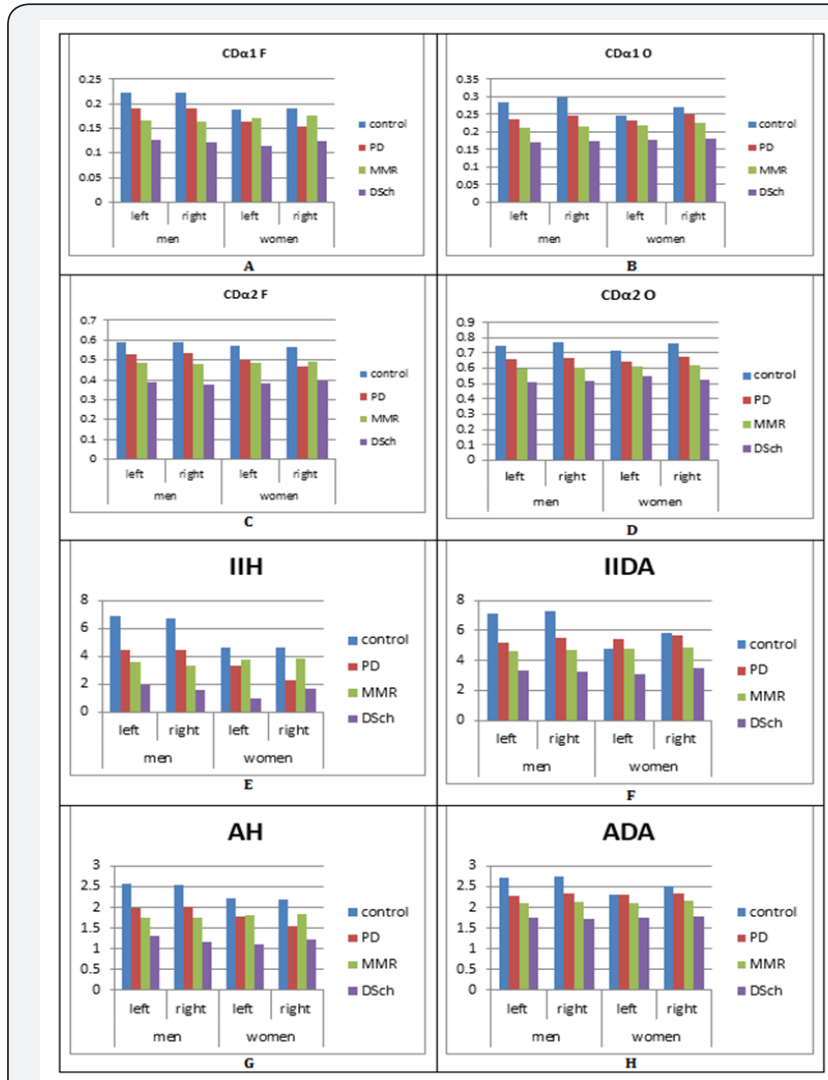

Figure 5: Comparative histograms of average values of indices DAFCAR at the debut of schizophrenia (explanation in the text discussion).

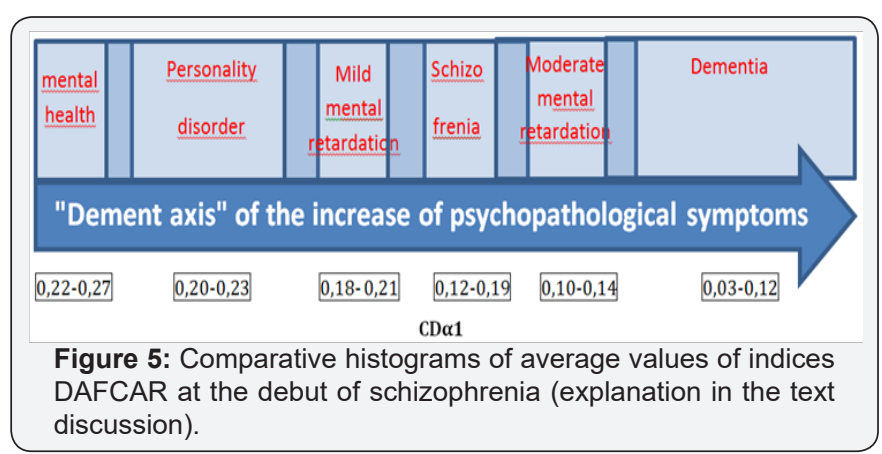

The only exception in this series - the difference between the values of modal frequencies in the frontal and occipital electrodes - it increases to schizophrenia. The differences in the personality disorder and slight mental retardation are insignificant and do not exceed the sensitivity threshold of the instrument $(0.25 \mathrm{~Hz})$, that is, they can be neglected and consider that in this pathology the synchronicity of the alpha rhythm is not broken. Despite the fact that the overall pattern of these indices is almost linear decline in the series from PD to DSch, the significance of them are different and they do not replace but complement each other.

CD 11 (Figure 5A - frontal electrodes, 5B - the occipital electrodes) is the main factor characterizing the qualitative characteristics of the spectrum of the alpha rhythm - the degree of split the lower the coefficient, the greater the degree of split. The disadvantage is a significant degree of scatter around the Central value (CV\% of about $30 \%$ in various studies). $\mathrm{CD} \alpha 2$ (Figure 5, C - frontal electrodes, D - occipital electrodes) reflects 
all the trends reflected by the coefficient $\mathrm{CD} \alpha 1$ and more resistant to statistical noise, but unfortunately, it is impossible to make dispersion diagrams, which are constructed according $\mathrm{CD} \alpha 1$.

IIG (Figure 5E) and IIDA (Figure 5F) reflect the overall "scatter" of the individual indicators around the Central value because it is one of the parameters of a normal distribution kurtosis. It shows the degree of split of the alpha rhythm over the entire range of 7-13 Hz in the occipital (IIDA) and frontal (IIH) leads. Its main disadvantage is a very high range of observations around the Central value, so in statistical comparisons it is better to use not the average value, the median of this value in the sample.

More stable and a very important indicator, which is able in the early stages to indicate the beginning of the dispersion of violations of the alpha rhythm - the ratio $\mathrm{AH}$ (in the frontal leads) (Figure 5G), and ADA (in the occipital leads) (Figure 5H). He starts to decrease in pathology when the modal value is still in the normal range. This phenomenon is particularly pronounced when personality disorder and delayed physiological development first appears at the onset of schizophrenia. Unfortunately, due to the low familiarity of doctors with the methods DAFCAR to identify schizophrenia at this early stage is very difficult - none of the doctors assigns of such studies.

Thus, the leading of the mechanism of formation of mental disorders in schizophrenia should be considered functional asynchrony of activity of the frontal lobes relative to other parts of the brain. In the present study were considered in the frontal and occipital lobes. Consideration of other departments is difficult and exceeds the technical capabilities of the experimenter. This is manifested by slowing of the alpha rhythm in the frontal derivations of the EEG. Signs of slowing down are not only the decreasing values of modal frequency, but the increase in scatter of capacity fluctuations in the spectrum of the alpha rhythm, with the result that he becomes multimodal and violate the normality of the distribution of these values. On the map it shows the Central displacement of the frontal complex of the cartogram to the left relative to the Central occipital complex. This disturbed stratification cartogram - areas it is washed away, color them in the Central part passes from yelloworange coloration in the blue-violet.

Parameters DAFCAR significantly change major indices decrease, indicating the increase of the split spectrum of the alpha rhythm, and, therefore, reduced functional ability NGNB, mainly in frontal departments. The modal frequency of the alpha rhythm in the frontal divisions is reduced, with the result that the difference between the frontal and occipital departments becomes more than $0.5 \mathrm{~Hz}$, often more than 0.75 Hz. Such schizoid disorders in NGNB are observed not only in the context of schizophrenia. Of course, with the development of the methodology, it will be possible to differentiate certain clinical variants of such changes probably, it in the severity of dispersion and topical features of their location.

Currently found the following. Synchronization of activities of individual sections of the NGNB is a strictly controlled process, because it is impossible without an effective afferent synthesis [16]. At decrease in functional capacity of the frontal lobes, which is manifested by slowing of the alpha rhythm, the encoding process is so broken that it leads to adequacy efferent reactions and even psychosis. The brain counteracts this process, including the timing mechanism, the main element of which is a stress mechanism of sympathetic regulation. Therefore, in the early stages of the emergence of variance violations appears "supersynchronous" "disturbing" pattern of the EEG. It manifests itself spilled the alpha rhythm. The difference between conventional brain activation from compensatory elimination of variance is a reaction to hyperventilation - when masked variance of the alpha rhythm as the result of increase of entropy appears NGNB endogenous reaction, which increases the variance of the alpha rhythm [17-19].

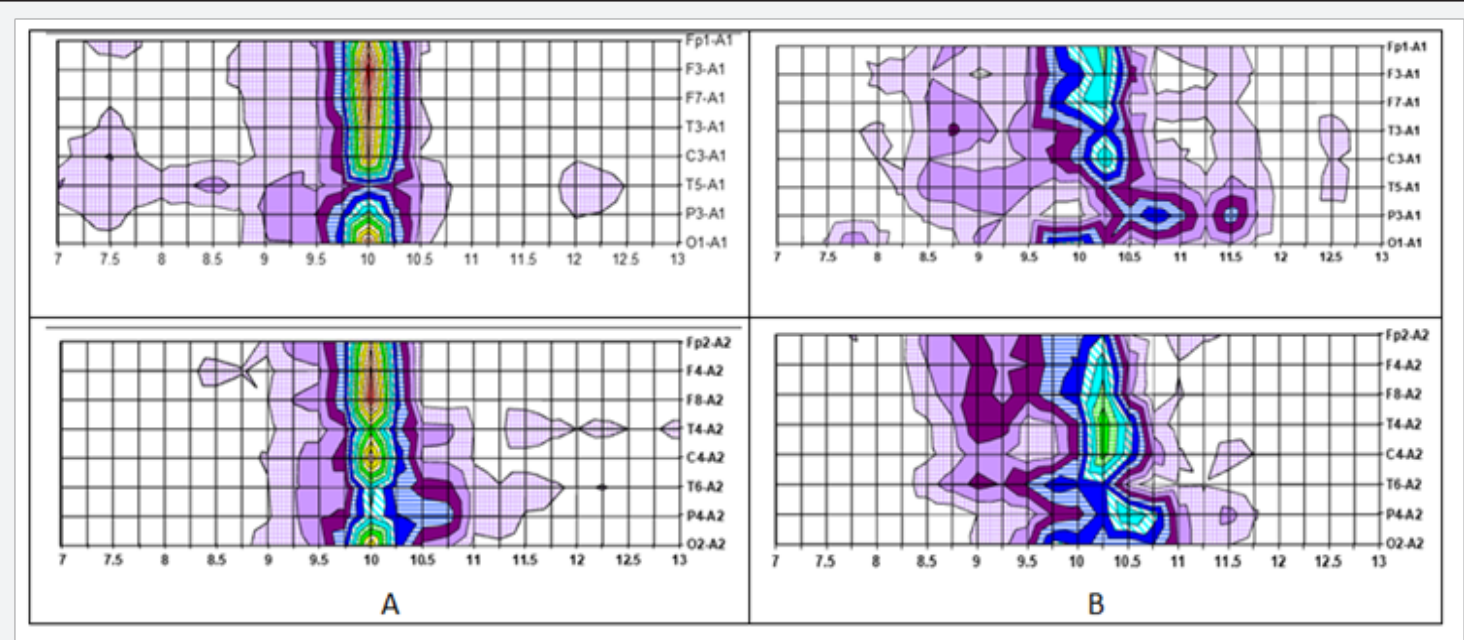

Figure 7: Identification of sub compensated endogenous adjustment of NGS GM at "super synchronous" alpha rhythm with the help of a HVT. A- Map in the background, B - after HVT. 


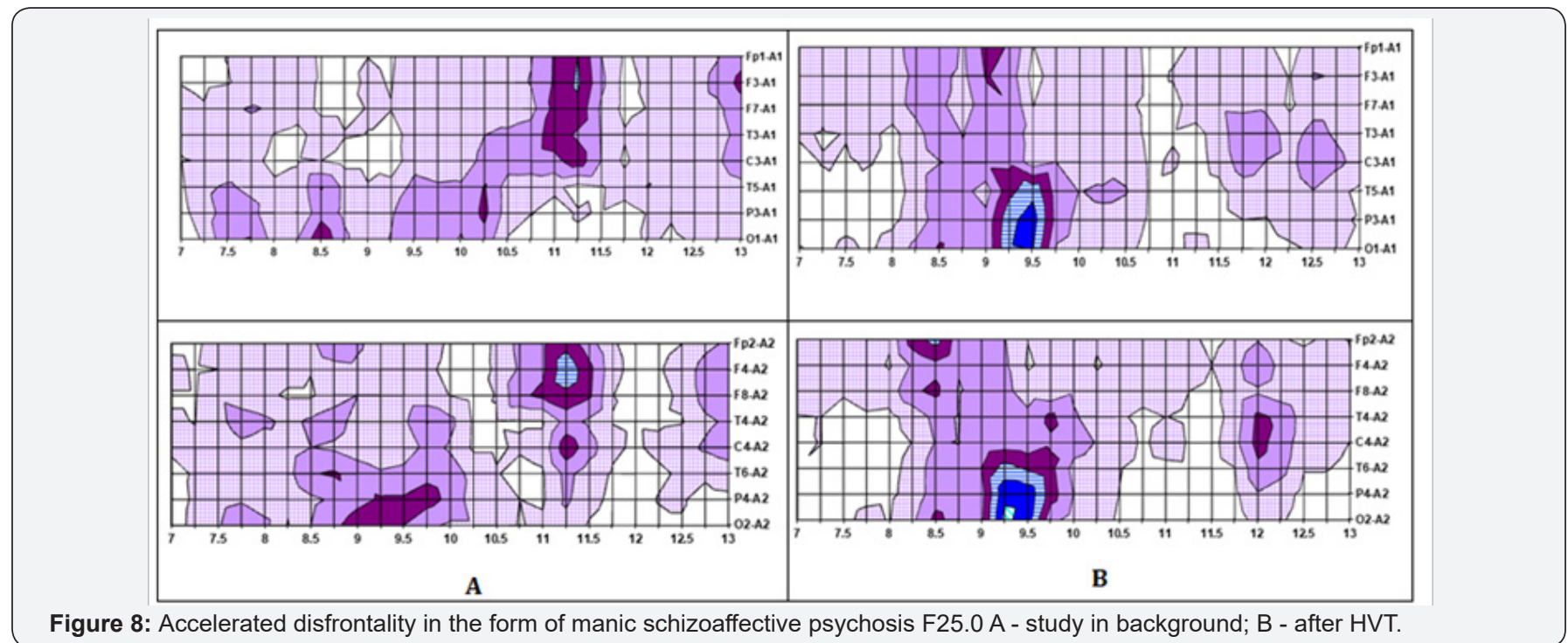

Figure 7 shows such a masked dispersion of alpha rhythm in a patient who underwent forensic psychiatric examination of recurring deviant behavior and multiple thefts clinically established diagnosis: "Paranoid schizophrenia." Previous articles have already pointed to the importance of HVT for the diagnosis of borderline states [18] and the prevention of violent crimes [15]. It is possible, that because of certain circumstances schizoid restructuring NGNB may occasionally occur in individuals with latent pathology in NGNB, with the result that they can experience an attack of schizophrenia. Thus, the schizophrenic process may be transient or latent flowing, however, in all these cases - and in latent, and symptomatic clinical form, everywhere we see the typical neurophysiological changes, signs of increasing DAFCAR with the phenomena of severe hypofrontality. However, hypofrontality is not the only option changes in the frontal lobes, leading to mental illness in Figure 8 shows a so-called case of accelerated disfrontality (my term) the patient with manic variant of schizoaffective psychosis (F25.0 Schizoaffective disorder, manic type).

Thus, supersynchronous of the alpha rhythm and its accompanying anxiety-depression may be a signal of increasing entropy changes NGNB and sign of depletion of compensatory abilities of the brain to contain them. Of course, there is probably a number of other violations related to the entropy of the brain and schizophrenia, what causes the incredible variability of this disease. However, the technique DAFCAR allows you to look into the "kitchen" of these processes, identify their differences with the aim of studying the schizophrenia and the search for new methods of treatment of this disease. Of course, such studies and the detection of debut of schizophrenia in early stages can be greatly facilitated by applying the new device - "Detector of the neuropsychiatric disorders" produced by MCS (Zelenograd, Russia), which gives the dispersion diagrams and indexes DAFCAR in automatic mode and the application which does not require specially trained personnel to decrypt the data of a EEG study.

\section{Conclusion}

a. Schizophrenia - a mental illness, which is caused by entropy NBNB special type, in which prevails the defeat of the frontal lobes with a strong regional disorganization of the functions of the frontal lobes, pre evaluate significant slowing of alpha-rhythm with development of severe functional hypofrontality.

b. Using the method of identifying DAFCAR at the onset of schizophrenia is determined by a significant increase in the representation of the non-REM part of the alpha rhythm in the frontal divisions, resulting in a modal value of it in relation to the occipital derivations is reduced to $0.75 \mathrm{~Hz}$ or more, and the index of dispersion is moderately reduced, resulting in comes the functional hypofrontality.

c. Schizophrenic symptoms may occur in a latent form for some time under the guise of protective reactions of the brain. Such masked and clinically erased forms can be identified by hyperventilation test EEG.

\section{Reference}

1. American Association on Mental Retardation (2002) Definition, classification and systems of supports $\left(10^{\text {th }} \mathrm{Ed}\right)$. American Association on Mental Retardation, Washington, DC, USA.

2. American Psychiatric Association, (2004) Diagnostic and Statistical Manual of Mental Disorders, Text Revision, (4 $4^{\text {th }}$ Ed) Revised. American Psychiatric Association, Washington, DC, USA.

3. Annett M, Kilshaw D (1983) Right- and left-hand skill estimating the parameters of the distribution of $\mathrm{L}-\mathrm{R}$ difference in male and female. $\mathrm{Br}$ J Psychol 74: 269-282.

4. Basar E, Schurmann M, Karakas S (1997) Alpha oscillations in brain functioning: an integrative theory. Int J Psychophysiol 26(1): 5-15.

5. (2013) Diagnostic and Statistical Manual of Mental Disorders, $5^{\text {th }}$ edition (DSM-5). American Psychiatric Association Washington, DC, USA.

6. Ivanov LB (2005) Applied computer electroencephalography. M.: MBN, 251 p.(In Rus) 
7. Iznak AF (1989) Modulation of sensory-motor human activity on the background of alpha-rhythm EEG. Problems of development of scientific research in the field of mental health 3-24.(In Rus)

8. Johannisson $T$, Nilsson $H$ (1996) The alpha rhythm in the electroencephalogram: a theory based on a neurophysiological model. Med Hypotheses 46(6): 557-561.

9. Kennard MA, Levy S (1952) The meaning of the abnormal electroencephalogram in schizophrenia. J Nerv Ment Dis 116(5): 413-425.

10. Klimesch W (1999) EEG alpha and theta oscillations reflect cognitive and memory performanse: a review and analysis. Brain Res Rev 29: 169-195.

11. Knyazeva MG, Jalili M, Meuli R (2008) Alpha rhythm and hypofrontality in schizophrenia. ActaPsychiatr Scand 118(3): 188-199.

12. Livanov MN (1984) Rhythms of the electroencephalogram and their functional significance. Journal of higher nervous activity 34(4): 613621.

13. Melnikova TS, Sarkisyan VV, Gurovich I Ya (2013) EEG alpha-rhythm in the first episode of paranoid schizophrenia. Social and clinical psychiatry 23(1): 40-45 (In Rus).

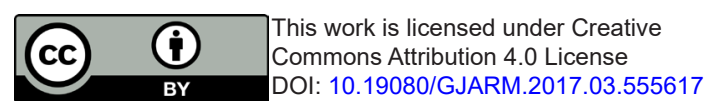

14. Riley EME, McGovern D, Mocker D (2013) Neuropsychological functioning in first episode psychosis - evidence of specific deficit. Schizophr Res 43: 47-55.

15. Rosman S, Kurakhina O (2017) Violent Crime in the Context of Entropy Neuron-Glial Networks of the Brain. Glob J Add \& Rehab Med 2(5): 555599.

16. Rosman S (2017) The Theoretical Foundations of Dispersion of Amplitude-Frequency Characteristics of the Alpha Rhythm of the EEG. Glob J Add \& Rehab Med 2(3): 555587.

17. Rosman S (2017) The Use of Analysis of Variance of the Alpha Rhythm of the EEG in the Study of the Pathogenesis of Alcoholism and the Causes of Alcoholic Deliria. Glob J Add \& Rehab Med 2(1): 555580.

18. Rosman SV (2017) Borderline Personality Disorder in the Context of Entropy Neuron-Glial Networks of the Brain. Glob J Add \& Rehab Med 2(4): 555595

19. Sugerman AA, Goldstein L (1972) The EEG in schizophrenia. Am J Psychiatry 128(11): 1466-1467.

\section{Your next submission with Juniper Publishers will reach you the below assets}

- Quality Editorial service

- Swift Peer Review

- Reprints availability

- E-prints Service

- Manuscript Podcast for convenient understanding

- Global attainment for your research

- Manuscript accessibility in different formats

( Pdf, E-pub, Full Text, Audio)

- Unceasing customer service

Track the below URL for one-step submission https://juniperpublishers.com/online-submission.php 